\title{
Theoretical studies on the conformations of selenamides
}

\author{
RAJNISH MOUDGIL, DAMANJIT KAUR, RACHITA VASHISHT and \\ PRASAD V BHARATAM* \\ Department of Chemistry, Guru Nanak Dev University, Amritsar 143005 , \\ India \\ e-mail: bharatam@jla.vsnl.net.in
}

MS received 10 April 2000; revised 24 October 2000

\begin{abstract}
A $b$ initio $\mathrm{HF} / 6-31+G^{*}, \mathrm{MP} 2 / 6-31+G^{*}$, B3LYP/6-31+ $G^{*}$ level calculations have been performed on $\mathrm{HSe}-\mathrm{NH}_{2}$ to estimate the $\mathrm{Se}-\mathrm{N}$ rotational barriers and $\mathrm{N}$-inversion barriers. Two conformers have been found with syn and anti arrangement of the $\mathrm{NH}_{2}$ hydrogens with respect to $\mathrm{Se}-\mathrm{H}$ bond. The $\mathrm{N}$ inversion barriers in selenamide are $1.65,2.47,1.93 \mathrm{kcal} / \mathrm{mol}$ and the $\mathrm{Se}-\mathrm{N}$ rotational barriers are 6.58 , 6.56 and $6.12 \mathrm{kcal} / \mathrm{mol}$ respectively at $\mathrm{HF} / 6-31+G^{*}$, MP2/6-31+G* and B3LYP/6$31+G^{*}$ levels respectively. The $n_{\mathrm{N}} \rightarrow \sigma^{*}$ Se-H negative hyperconjugation is found to be responsible for the higher rotational barriers.
\end{abstract}

Keywords. Selenamides; Se-N interactions; conformations; ab initio calculations.

\section{Introduction}

There is increasing interest in the chemistry of organoselenium compounds. Several selenols, selenones, selenoamides, selenonium ylides, selenonium imides etc. have been studied in comparison with organosulphur compounds ${ }^{1}$. Compounds containing $\mathrm{Se}-\mathrm{N}$ bonds are rare. Flemmang $e t a l^{2}$ have reported the generation of nitrile $\mathrm{N}$-selenides in the gas phase, which have $\mathrm{Se}-\mathrm{N}$ ionic interactions. They also reported the generation of pyridine $\mathrm{N}$-selenide in the gas phase ${ }^{3}$. Kamigata et $a l^{4-6}$ have reported the syntheses, kinetics, optical activity and $\mathrm{Se}-\mathrm{N}$ interactions of selenonium imides and $\mathrm{R}_{2} \mathrm{Se}=\mathrm{NR}$ with the $\mathrm{Se}-\mathrm{N}$ hypervalent bond. In contrast, no theoretical studies have been reported on selenamides (also known as selenenamide and selenohydroxylamine) RSe-NR 2 with $\mathrm{Se}-\mathrm{N}$ single bond. It is especially intriguing because the corresponding sulphenamides ${ }^{7}$ RS-NR 2 are well-known, their chiroptical properties are well-studied ${ }^{8}$ and sulphenamides are also reported to show a very strong anomeric effect ${ }^{9}$. In our laboratory, we have been studying the bonding characteristics of selenoamides, isoselenocyanates etc. to understand the bonding in organoselenium complexes ${ }^{10}$ and also on $\mathrm{S}-\mathrm{N}$ interactions ${ }^{11}$.<smiles>[R][Se]N([R])[R]</smiles>

*For correspondence 

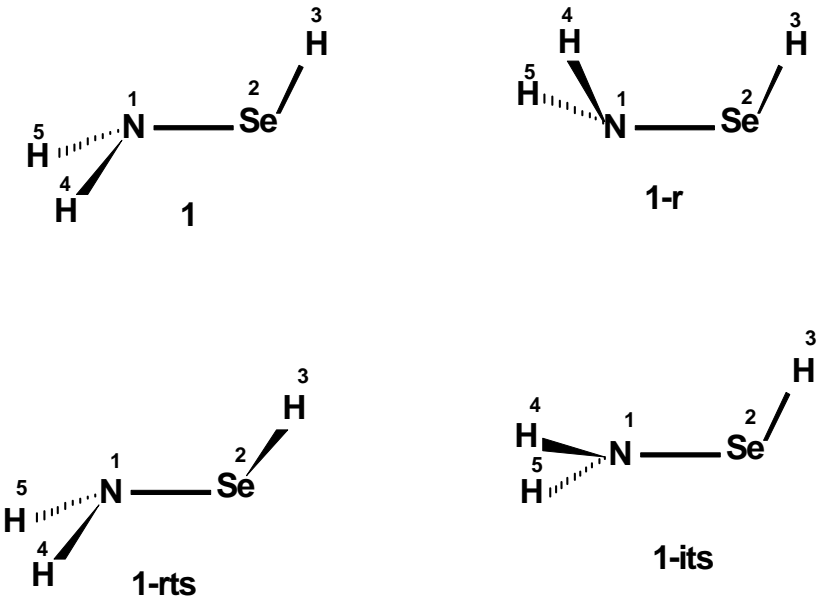

Figure 1. Conformations of selenamides, $\mathrm{HSe}-\mathrm{NH}_{2}$.

In continuation of our efforts, we present studies on the conformational preferences of selenamide, $\mathrm{HSe}-\mathrm{NH}_{2}$ (figure 1), using theoretical methods.

\section{Methods of calculation}

$A b$ initio $^{12}$ and density functional ${ }^{13}$ (DFT) calculations have been carried out using the Gaussian94W ${ }^{14}$ package, the Windows version of the Gaussian94 suite of programs, on an IBM compatible PC Pentium-100 MHz with $64 \mathrm{MB}$ memory and $1 \mathrm{~GB}$ disk space. Complete optimizations have been performed using HF/6-31+G* basis set. Inclusion of polarization functions in the basis set were found to be important because of the presence of several lone pairs of electrons (in figure 1) ${ }^{12 a}$. To study the effect of electron correlation on the geometries and energies, complete optimizations have been carried out using MP2(full)/6-31+ $G^{*}$, B3LYP/6-31+ $G^{* 15}$ levels also. Frequencies were computed analytically for all optimized species at $\mathrm{HF} / 6-31+G^{*}$ level in order to characterize each stationary point as a minimum or a transition state and to determine the zero point vibrational energies (ZPE). The frequencies and ZPE values obtained at $\mathrm{HF} / 6-31+G^{*}$ level have been scaled by a factor of $0.9153^{16}$. Atomic charges in all the structures were obtained using the natural population analysis (NPA) method within the natural bond orbital approach ${ }^{17-18}$.

\section{Results and discussion}

On the potential energy surface of selenamide, $\mathrm{HSe}-\mathrm{NH}_{2}$, two minima, 1, 1-r, one rotational transition state, 1-rts, and one inversion transition state 1-its could be located (figure 1). Data corresponding to these structures obtained using $\mathrm{HF} / 6-31+G^{*}$, MP2(full)/6-31+ $G^{*}$, B3LYP/6-31+ $G^{*}$ level are given in table 1 . Both the ground state structures 1 and 1-r are found to have $C_{s}$ symmetry. The basic difference between the two structures arises from the arrangement of the $\mathrm{NH}_{2}$ group, syn or anti with respect to the 


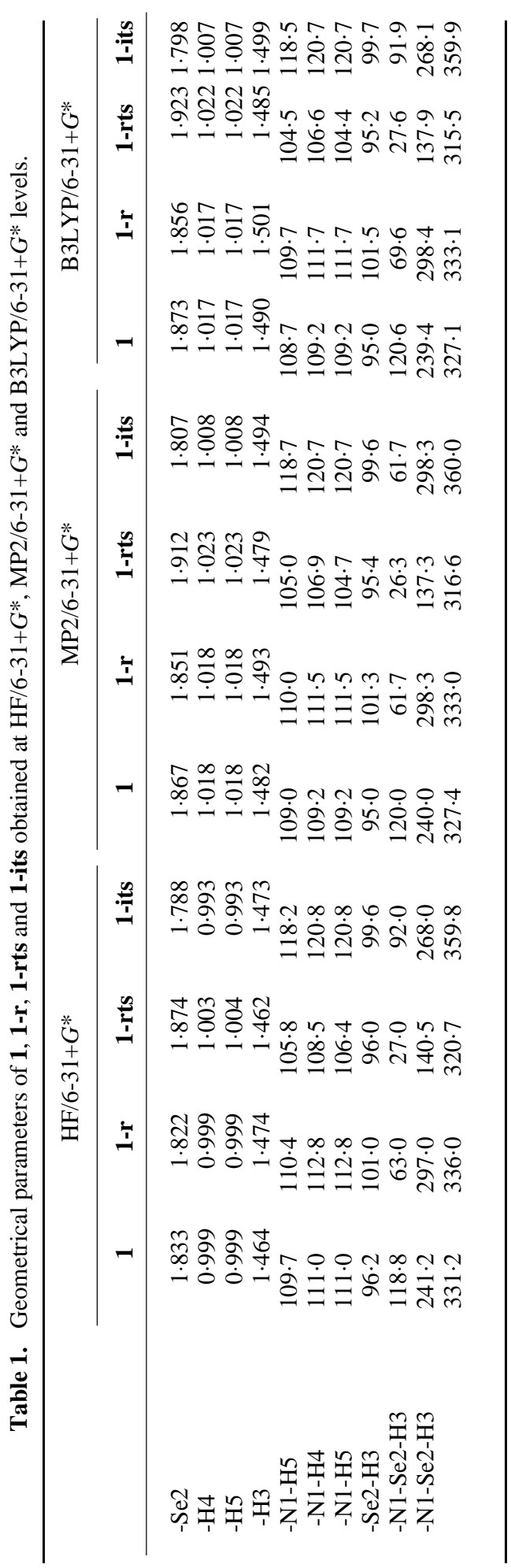


$\mathrm{Se}-\mathrm{H}$ bond. The $\mathrm{Se}-\mathrm{N}$ bond length in $\mathbf{1}$ is $1.833 \AA$ at $\mathrm{HF} / 6-31+G^{*}$ level, this distance increases to $1.867 \AA$ and $1.873 \AA$ after including electron correlation at MP2 and B3LYP levels respectively. This is consistent with the earlier observations that inclusion of electron correlation overestimates the $\mathrm{S}-\mathrm{X}$ bond lengths ${ }^{19}$. The calculated $\mathrm{Se}-\mathrm{N}$ stretching frequencies for $\mathbf{1}$ and $\mathbf{1 - r}$ at $\mathrm{HF} / 6-31+G^{*}$ level are 603.37 and $603.7 \mathrm{~cm}^{-1}$ (table 5) with IR intensities 67.35 and 100.86 respectively.

The $\mathrm{N}-\mathrm{Se}-\mathrm{H}$ angle in $\mathbf{1} \sim 95.0^{\circ}$ is very small as expected for divalent selenium. The nitrogen is $s p^{3}$ hybridized and is highly pyramidalized as indicated by the sum of angles $\left(327 \cdot 4^{\circ}\right.$ at MP2/6-31+G* level) around nitrogen in 1. In 1-r also, the $\mathrm{N}$ atom has pyramidal arrangement but to a lesser degree (sum of angles is $333 \cdot 0^{\circ}$ ). At all levels of theory, the Se-N bond length in 1-r is smaller than that in $\mathbf{1}$. The reduction in Se-N bond length from 1 to 1-r is larger at the electron-correlated levels. In the rotational transition state 1-rts, the $\mathrm{Se}-\mathrm{N}$ bond length is elongated by $\sim 0.05 \AA$. In 1-rts, the pyramidal character has increased as expected, the sum of angles around nitrogen is $316 \cdot 6^{\circ}$. The inversion transition state 1-its has $C_{s}$ symmetry with a planar arrangement around nitrogen. The Se-N bond in 1-its is shorter than that in $\mathbf{1}$ by $\sim 0.06 \AA$. These variations in the $\mathrm{Se}-\mathrm{N}$ bond lengths during rotation and inversion can be attributed to the variation in the $n_{N} \rightarrow \sigma *_{\text {Se-H }}$ negative hyperconjugation.

The absolute energies and the ZPE values of $\mathbf{1}$ and the related structures are given in table 2 , while the relative values are given in table 3 . The energy difference $(\Delta E)$ between the two minima are only $0.06,0.24$ and $0.03 \mathrm{kcal} / \mathrm{mol}$ at $\mathrm{HF} / 6-31+G^{*}$, MP2 $/ 6-31+G^{*}$, and B3LYP/6-31+G* levels respectively. The calculated inversion barriers in $\mathbf{1}$ are 1.65 , 2.47 and $1.93 \mathrm{kcal} / \mathrm{mol}$ at these three levels respectively. These smaller $\Delta E$ values and inversion barriers indicate that there is no preference for any one of the structures at room temperature. The smaller $\mathrm{N}$-inversion barriers can be attributed to the increased anomeric effect, which stabilizes the transition structure 1-its. The increase in negative

Table 2. Absolute energies (in a.u.) and zero point vibrational energies (ZPE in $\mathrm{kcal} / \mathrm{mol}$ ) of 1, 1-r, 1-rts and 1-its obtained at various levels.

\begin{tabular}{lcccc}
\hline Method & 1 & 1-r & 1-rts & 1-its \\
\hline HF/6-31+G & -2453.527858 & - & -2453.51280 & - \\
HF/6-31+G* & -2453.7611670 & -2453.761364 & -2453.749850 & -2453.757027 \\
MP2/6-31+G* & -2454.042140 & -2454.042620 & -2454.030846 & -2454.036703 \\
B3LYP/6-31+G* & $-2455 \cdot 929739$ & -2455.929591 & -2455.919147 & -2455.925150 \\
ZPE $^{\Theta}(\mathrm{NIF})$ & $23.04(0)$ & $22.04(0)$ & $22.52(1)$ & $22.10(1)$ \\
\hline
\end{tabular}

\footnotetext{
${ }^{\circledR}$ Obtained at HF/6-31+G* level and scaled by 0.9153 ; NIF: number of imaginary frequencies
}

Table 3. The difference $(\Delta E)$ between 1 and 1-r, the rotation and inversion barriers in $\mathbf{1}$ obtained at various levels. The ZPE corrected values are given in parentheses.

\begin{tabular}{lccc}
\hline Method & \multicolumn{1}{c}{$\Delta E$} & Rotation barriers & Inversion barriers \\
\hline $\mathrm{HF} / 6-31+G$ & - & $9.44(8.92)$ & - \\
$\mathrm{HF} / 6-31+G^{*}$ & $0.12(0.06)$ & $7 \cdot 10(6.58)$ & $2.60(1.65)$ \\
MP2/6-31+G* & $0.30(0 \cdot 24)$ & $7.09(6.56)$ & $3.41(2.47)$ \\
B3LYP/6-31+G* & $0.09(0.03)$ & $6.65(6 \cdot 12)$ & $2.88(1.93)$ \\
\hline
\end{tabular}


hyperconjugation in 1-its is evidenced by the decrease in $\mathrm{Se}-\mathrm{N}$ distance, increase in $\mathrm{Se}-\mathrm{N}$ bond polarization (table 4 ) and increase in the $\mathrm{N}-\mathrm{Se}-\mathrm{H}$ and $\mathrm{Se}-\mathrm{N}-\mathrm{H}$ angles in $\mathbf{1}$-its as compared to those in $\mathbf{1}$.

The Se-N rotational barrier in 1 at $\mathrm{HF} / 6-31+G^{*}(+\mathrm{ZPE})$ level is $6.58 \mathrm{kcal} / \mathrm{mol}$. Inclusion of electron correlation using second-order Moller-Plesset perturbation method decreases the rotational barrier by a small amount $(6.56 \mathrm{kcal} / \mathrm{mol})$. Inclusion of electron correlation using density functional B3LYP method decreases the Se-N rotational barrier to $6.12 \mathrm{kcal} / \mathrm{mol}$. The $\mathrm{Se}-\mathrm{N}$ rotational barrier in $\mathbf{1}$ is less than the $\mathrm{S}-\mathrm{N}$ rotational barrier in sulphenamide, $\mathrm{HS}-\mathrm{NH}_{2}\left(7.97,8.04,7.63 \mathrm{kcal} / \mathrm{mol}\right.$ at $\mathrm{HF} / 6-31+G^{*}, \mathrm{MP} 2 / 6-31+G^{*}$, B3LYP/6-31+G* levels respectively). The high rotational barriers in sulphenamides have been attributed mainly to the $n_{N} \rightarrow \sigma^{*}{ }_{\mathrm{S}-\mathrm{H}}$ negative hyperconjugation. The $\mathrm{Se}-\mathrm{N}$ rotational barrier in $\mathbf{1}$ is also much larger than is expected for a simple single bond (for example, rotational barrier in $\mathrm{C}-\mathrm{C}$ single bond is about $3 \mathrm{kcal} / \mathrm{mol}$ ). Hence, it can be expected that selenamides also show anomeric effects like sulphenamides, albeit to a smaller extent. The reduced $\mathrm{Se}-\mathrm{N}$ rotation barrier might be due to smaller anomeric effect in $\mathbf{1}$, which may arise from the longer bond length (Se-N: $1.833 \AA$ in $\mathbf{1}$ and $\mathrm{S}-\mathrm{N}: 1.709 \AA$ in HS-NH both at HF/6-31+ $G^{*}$ level), which in turn originates from the larger size of selenium.

The $d \pi-p \pi$ interactions do not seem to play any important role in $\mathrm{Se}-\mathrm{N}$ interactions. NBO analysis showed that the selenium $d$ orbital occupation in 1, 1-r, 1-rts and 1-its respectively at MP2/6-31+G* level are 0.07, 0.07, 0.07 and 0.06. The inclusion of $d$ functions are important so as to polarize the Se-H $\sigma^{*}$ orbital, but not to cause $d \pi-p \pi$

Table 4. NPA charges in 1 and its conformations obtained at MP2/6-31+G* level using MP2 densities.

\begin{tabular}{lrrrr}
\hline Atoms & $\mathbf{1}$ & $\mathbf{1 - r}$ & 1-rts & 1-its \\
\hline N1 & $-1 \cdot 109$ & $-1 \cdot 114$ & -1.073 & $-1 \cdot 195$ \\
Se2 & 0.206 & 0.249 & 0.197 & 0.287 \\
H3 & 0.078 & 0.042 & 0.072 & 0.047 \\
H4 & 0.412 & 0.412 & 0.400 & 0.431 \\
H5 & 0.412 & 0.412 & 0.403 & 0.431 \\
4d occupancy & 0.07 & 0.07 & 0.07 & 0.06 \\
\hline
\end{tabular}

Table 5. Frequencies $\left(\mathrm{cm}^{-1}\right)$ of different normal modes of vibration in $\mathbf{1}$ and 1-r of selenohydroxylamine at $\mathrm{HF} / 6-31+G^{*}$ level.

\begin{tabular}{lcc}
\hline Normal modes & $\mathbf{1}$ & $\mathbf{1 - r}$ \\
\hline Torsion & $411 \cdot 7$ & $446 \cdot 1$ \\
Se-N stretching & $603 \cdot 3$ & $603 \cdot 7$ \\
Scissoring & $786 \cdot 4$ & $771 \cdot 9$ \\
N-Se-H bending & $999 \cdot 1$ & $897 \cdot 7$ \\
Twisting & $1081 \cdot 2$ & $1065 \cdot 8$ \\
Wagging & $1645 \cdot 1$ & $1633 \cdot 1$ \\
Se-H stretching & $2361 \cdot 2$ & $2307 \cdot 7$ \\
N-H stretching symmetric & $3447 \cdot 2$ & $3444 \cdot 7$ \\
N-H stretching asymmetric & 3541.5 & 3543.7 \\
\hline
\end{tabular}

These values are scaled by a factor of 0.9153 
interactions ${ }^{9}$. If $d \pi-p \pi$ interactions are important between selenium and nitrogen, the $\mathrm{Se}-\mathrm{N}$ rotational barrier should be considerably higher in $\mathbf{1}$ when the $d$-orbitals are included as compared to the Se-N rotational barrier when they are not included. The $\mathrm{Se}-$ $\mathrm{N}$ rotational barrier in 1 at $\mathrm{HF} / 6-31+G$ level is $8.92 \mathrm{kcal} / \mathrm{mol}$ which is larger than the $\mathrm{Se}-$ $\mathrm{N}$ rotational barrier obtained at $\mathrm{HF} / 6-31+G^{*}$ level $(6.58 \mathrm{kcal} / \mathrm{mol})$. Thus, $d$-orbital participation does not increase the rotational barriers, indicating that $d \pi-p \pi$ interactions are not responsible for the rotational barriers in $\mathbf{1}$.

Atomic charges obtained by using the NPA method are given in table 4 . The data clearly indicate that the $\mathrm{N}$ atom has a unit negative charge whereas the selenium is only slightly positive. In 1-r, the negative charge on nitrogen slightly increases and the positive charge on selenium increases by 0.043 units, i.e. $\mathrm{Se}-\mathrm{N}$ bond polarization increases. Variation in the geometrical parameters of $\mathbf{1}$ and $\mathbf{1 - r}$ indicate relatively more anomeric effect in 1-r conformation. The change in charge distribution on nitrogen and selenium may be the result of change in hybridization of nitrogen in 1-r (closer to $s p^{2}$ ) as indicated by change in the $\mathrm{N}-\mathrm{Se}-\mathrm{H}$ and $\mathrm{Se}-\mathrm{N}-\mathrm{H}$ angles. Because of this increase in the polarization, the electrostatic attraction between selenium and nitrogen increases which finally leads to a decrease in the $\mathrm{Se}-\mathrm{N}$ distance. This is in accordance with the negative hyperconjugation present in these systems. In the inversion transition state 1-its, the $s$ character and electronegativity of $\mathrm{N}$ is more than that in $\mathbf{1}$, resulting in increase in the charge at $\mathrm{N}$ and reduction in $\mathrm{Se}-\mathrm{N}$ bond length. This analysis indicates that the smaller $\mathrm{Se}-\mathrm{N}$ bond distances in selenamides with almost planar arrangement on nitrogen are due more to the increased charge separation between $\mathrm{Se}$ and $\mathrm{N}$ rather than to the increase in charge transfer from $\mathrm{N}$ to Se through $d$-orbital interactions as well as the enhanced anomeric effect.

\section{Conclusions}

Complete optimizations using SCF, MP2, B3LYP methods and $6-31+G^{*}$ basis set show that the $\mathrm{Se}-\mathrm{N}$ in selenamides has a slightly larger $\mathrm{Se}-\mathrm{N}$ rotational barrier. This is mainly due to the $n_{\mathrm{N}} \rightarrow \sigma^{*}$ Se-H negative hyperconjugation present in $\mathbf{1}$. The Se-N bond length is of the order of $1.86-1.87 \AA$. The negative hyperconjugation in $\mathbf{1}$ is less than that in sulphenamides, mainly due to the larger size of selenium as compared to that of sulphur. The $\mathrm{N}$-inversion barrier is small, which indicates that the two conformers are indistinguishable at room temperature.

\section{Acknowledgements}

The authors thank the Department of Science and Technology, New Delhi for financial support.

\section{References}

1. Whitham G H 1995 Organosulphur chemistry (New York: Oxford University Press) p. 85

2. Gerbaux P, Flammang R, Morkved E H, Wong M W and Wentrup C 1998 Tetrahedron 39533

3. Flemmang R 1999 Int. J. Mass Spectrosc. Ion Process. 18439

4. Shimizu T, Kamigata N and Ikuta S 1999 J. Chem. Soc., Perkin Trans. 21469

5. Shimizu T, Seki N, Taka H and Kamigata N 1996 J. Org. Chem. 616013

6. Kamigata N, Taka H, Matsuhisa A, Matsuyama H and Shimizu T 1994 J. Chem. Soc., Perkin Trans. 12257 
7. Crain L and Raban M 1989 Chem. Rev. 89689

8. Blanca M B D, Maimon E and Kost D 1997 Angew. Chem., Int. Ed. Engl. 362216

9. Reed A E and Sheleyer P V R 1998 Inorg. Chem. 273969

10. Bharatam P V, Uppal P A and Bassi P S 1997 J. Chem. Phys 27631

11. (a) Bharatam P V, Uppal P A and Kaur D 2000 J. Chem. Soc., Perkin Trans. 2 43; (b) Bharatam P V, Uppal P A and Kaur D 2000 Indian J. Chem. B39 0000

12. (a) Hehre W J, Radom L, Schleyer P V R and Pople J A 1986 Ab initio molecular orbital theory (New York: Wiley-Interscience); (b) Foresman J B and Frisch E 1996 Exploring chemistry with electronic structure methods 2nd edn (Pittsburg: Gaussian)

13. (a) Parr R G and Yang W 1989 Density-functional theory of atoms and molecules (New York: Oxford); (b) Bartolotti I J and Fluchick K 1996 In Reviews in computational chemistry (eds) K B Lipkowitz and D B Boyd (New York: VCH) 17187

14. Gaussian 94W 1995 Revision B.2, M J Frisch et al, Gaussian, Inc. Pittsburgh PA

15. (a) Becke A D 1993 J. Chem. Phys. 98 5648; (b) Lee C, Yang W and Parr R G 1980 Phys. Rev. B37 785; (c) Perdew J P and Wang Y 1992 Phys. Rev. B45 13244

16. Scott A P and Radom L 1996 J. Phys. Rev. B45 16502

17. Reed A E, Weinstock R B and Weinhold F 1985 J. Chem. Phys. 83735

18. Reed A E, Curtiss A and Weinhold F 1988 J. Chem. Phys. 88899

19. Fabian J and Hess B A 1997 J. Org. Chem. 621766 